\title{
A PERSPECTIVA DOS ALUNOS COM DEFICIÊNCIA VISUAL SOBRE O ENSINO DE EMBRIOLOGIA NA EDUCAÇÃO BÁSICA
}

\author{
Niumaique Gonçalves da Silva ${ }^{1}$, Andressa Antônio de Oliveira ${ }^{2}$, Juliana Castro \\ Monteiro Pirovani ${ }^{1}$ \\ ${ }^{1}$ Departamento de Ciências Agrárias e Biológicas da Universidade Federal do Espírito \\ Santo, São Mateus, Brasil (niumaique@gmail.com). \\ ${ }^{2}$ Pós-Graduação em Ensino na Educação Básica da Universidade Federal do Espírito Santo, \\ São Mateus, Brasil
}

Recebido em: 06/04/2018 - Aprovado em: 10/06/2018 - Publicado em: 20/06/2018 DOI: 10.18677/EnciBio_2018A106

\begin{abstract}
RESUMO
O ensino de embriologia é visto como um desafio entre os professores e alunos pela escassez de material didático que auxilie na atribuição da informação verbal. $O$ conteúdo encontra-se restrito em textos e imagens nos livros didáticos e não atende ao contexto inclusivo dos alunos deficientes visuais. Neste sentido, este estudo propôs analisar como o conteúdo de Embriologia Humana tem sido trabalhado com alunos deficientes visuais matriculados em salas de ensino regular nas escolas estaduais do município de São Mateus-ES. Foram entrevistados três professores que atuam no ensino de Ciências e Biologia, um professor que atua na educação especial e quatro alunos deficientes visuais de três escolas estaduais do município de São Mateus-ES para conhecer a realidade escolar, o suporte pedagógico utilizado em sala e os desafios enfrentados na temática de inclusão. Constatou-se que o conteúdo de embriologia é ensinado de modo superficial com apoios limitados, oferecidos tanto pelas escolas quanto pelos docentes.
\end{abstract}

PALAVRAS- CHAVE: Educação inclusiva, ensino de biologia, prática pedagógica.

\section{THE PERSPECTIVE OF STUDENTS WITH VISUAL DEFICIENCY ON THE EDUCATION OF EMBRYOLOGY IN BASIC EDUCATION}

\begin{abstract}
The teaching of embryology is seen as a challenge among teachers and students due to the lack of didactic material that assists in the attribution of verbal information. The content is restricted in texts and images in textbooks and does not meet the inclusive context of the visually impaired students. In this matter, the study proposed to analyze how the content of Human Embryology has been worked with visually impaired students enrolled in regular teaching rooms in state schools in the municipality of São Mateus-ES. Were interviewed, three professors who participated in the teaching of Science and Biology, one teacher working in special education and four visual deficient students from three state schools in the same municipality above-mentioned, to know the school reality, the pedagogical support used in the classroom and the challenges faced in the regard of inclusion. It was found that embryology content is taught superficially with limited supports, offered by both schools and teachers.
\end{abstract}

KEYWORDS: Inclusive education, biology teaching, pedagogical practice. 


\section{INTRODUÇÃO}

Um dos grandes desafios de uma educação inclusiva atribui à escola a responsabilidade de deixar de excluir para incluir e educar a diversidade dos seus públicos, numa perspectiva de sucesso de todos e de cada um, independentemente da sua cor, raça, cultura, religião, deficiência intelectual, psicológica ou física (SÁNCHEZ, 2005).

Para isso, as reformas educacionais e todos os questionamentos sobre o papel da escola exigem que se repense a prática pedagógica tendo a ética, a justiça e os direitos humanos como um novo parâmetro de ação educativa para ensinar a todos os alunos, sem discriminação e com métodos e práticas de ensino especializado (MANTOAN, 2002) que devem adequar à nova realidade educacional através da construção de políticas e práticas institucionais e pedagógicas que garantam o incentivo da qualidade de ensino a todos (BRASIL, 2001).

Deste modo, compreender o papel da visão para o sucesso educativo é um passo importante para os educadores e professores. Já que os "alunos com baixa acuidade visual apresentam dificuldades para perceberem formas, sejam de perto, longe, ou em ambas as situações" (SOUZA et al., 2005). O aparelho visual:

[...] constitui um canal privilegiado de acesso ao mundo, constituindo a base de uma parte significativa das aprendizagens humanas. Através da visão as crianças desenvolvem-se e aprendem naturalmente, sem que tenham que ser ensinadas, unicamente pelo fato de observarem, explorarem e interagirem com o mundo que as rodeia. No caso das crianças cegas ou com graves limitações visuais, a informação visual é inexistente ou recebida de forma fragmentada e distorcida, o que limita a interação com o ambiente e a extensão e variedade das experiências, comprometendo as aprendizagens acidentais e originando atrasos no desenvolvimento motor, cognitivo e social (BRASIL, 2008).

Para Fernandes e Orrico (2008), as limitações de aprendizagem causadas pelas desordens geradas no aparelho visual por fatores congênitos ou adquiridas são compensadas pelos sentidos restantes, em um processo de substituição dos sentidos utilizados para interpretar o mundo de acordo as novas possibilidades e, no entanto, devem ser explorados nas práticas pedagógicas durante o preparo de aulas e atividades pelos profissionais da escola (PACHECO et al., 2007).

A utilização de recursos ópticos ${ }^{1}$ e não-ópticos ${ }^{2}$ para o ensino de alunos deficientes visuais constituem ferramentas fundamentais que auxiliam o processo de aprendizagem destes alunos nos diferentes conteúdos e disciplinas da educação básica. O ensino das estruturas microscópicas na disciplina de Ciências e Biologia concentram-se em instrumentos ópticos, textos explicativos e descritivos presente no livro, assim como as representações visuais táteis, somente visuais e/ou tátilvisuais, tanto para alunos que enxergam, quanto para deficientes visuais (BATISTETIL, et al., 2009).

\footnotetext{
${ }^{1}$ Recursos ou auxílios ópticos são lentes de uso especial ou dispositivo formado por um conjunto de lentes, geralmente de alto poder, com o objetivo de magnificar a imagem da retina.

${ }^{2}$ Os recursos não-ópticos modificam os materiais e melhoram as condições do ambiente com finalidade de aumentar a resolução visual. Esses recursos são utilizados mediante prescrição e orientação oftalmológica (BRASIL, 2007).
} 
O ensino de Embriologia Humana ministrado no ensino médio é avaliado como um obstáculo entre o docente e discente no ensino, pela falta de compreensão da complexidade de eventos que ocorrem no desenvolvimento do embrião em níveis micro e macroscópico e pela escassez de material didático (RODRIGUES et al., 2004; FREITAS et al., 2008; OLIVEIRA, 2015), como os modelos tridimensionais que representam as diversas fases embrionárias do desenvolvimento humano.

Com terminologias científicas que exige do visual dos alunos para o entendimento de uma gama de conceitos e significados para ajudar na construção abstrata da visualização mental (MATOS et al., 2010), a matéria apresenta-se restrita nos livros-textos e figuras ilustrativas, delimitando a compreensão anatômicoespacial dos processos ontogênicos (SOUZA; FARIA, 2011).

Silva et al. (2015) relatam que a apresentação do assunto de embriologia de forma sistêmica e contextual desmotiva o interesse do aluno e dificulta a aprendizagem do conteúdo, deixando-o num processo árduo, desestimulante e pouco prazeroso. Com isso, a utilização de ferramentas educacionais ativas como as práticas de desenhar, o uso de modelos embrionários, jogos didáticos e demais recursos contribuem para o processo de ensino-aprendizagem e na memorização dos diversos termos embriológicos (MAIA et al., 2017).

\section{REFERENCIAL TEÓRICO}

HISTÓRICO DA EDUCAÇÃO ESPECIAL NO BRASIL

O desenvolvimento histórico da Educação Especial seguiu de movimentos sociais e políticos voltados para o direito de acesso das pessoas com deficiência ao sistema educacional público. Antes era tida como um sistema paralelo e segregado de ensino, por agrupar profissionais, técnicos, recursos e metodologias específicas direcionadas a todas as crianças ou jovens cujas necessidades educacionais especiais se originam em função de deficiência ou dificuldade de aprendizagem (ABENHAIM, 2005; GLAT; BLANCO, 2009).

A institucionalização da Educação Especial no Brasil nas escolas de ensino regular aconteceu na década de 1970 com concepção prática-teórica de uma Educação Especial conduzida nos avanços da Pedagogia e da Psicologia da Aprendizagem, especialmente com enfoque no comportamental voltado para autonomia das atividades de vida diária. A preocupação manteve somente com o acesso dos deficientes no sistema educacional público, deixando-os relegados do processo de escolarização formal (GLAT; FERNANDES, 2005).

Mais tarde com a criação do Centro Nacional de Educação Especial (hoje Secretária de Educação Especial) no ano de 1973, novas metodologias e técnicas de ensino foram inseridas permitindo a aprendizagem e adaptação dos sujeitos, resultando numa mudança de paradigma predominado que "o deficiente pode aprender" (GLAT; BLANCO, 2009).

Essa nova mudança desenvolveu-se no paradigma educacional de Integração que pressupunha possibilidades de mudanças no nível do aluno, de modo a oferecer um ambiente escolar menos restritivo possível para os alunos com deficiência (MENDES, 2006). Porém, o processo de integração destes alunos na rede regular apresentou problemas no processo de implantação, por exigir uma 
preparação prévia do aluno para a inserção total na classe comum ou na classe especial auto-contida (MENDES et al., 2005).

Tal ocorrência fez surgir a Educação Inclusiva como uma nova perspectiva escolar que responda aos vários tipos de características e necessidades da diversidade do alunado através de alterações curriculares, pedagógicas e políticas como processo de inclusão que apoia o "[...] reconhecimento dos direitos civis de numerosas pessoas com deficiência que não têm acesso à educação ou que seguem segregados nos centros de educação especial" (SÁNCHEZ, 2005).

A concepção teórica e prática da Educação Especial transformada em Educação Inclusiva nas diretrizes nacionais para a educação de alunos com necessidades especiais na Educação Básica dos sistemas federais, estaduais e municipais constituiu a política educacional do país amparada na resolução CNE/CEB N² 2 de 2001 (GLAT; BLANCO, 2009).

Assim, novas percepções educacionais centradas no aluno, a fim de ministrar o ensino para um público heterogêneo e que atenda a necessidade de cada educando foram marcadas por medidas apoiadas na formação continuada de docentes e na produção e distribuição de material especializado como instrumentos que auxiliem na descoberta de metodologias alternativas para o benefício dos educandos (JUNIOR; HERNANDES, 2011).

\section{ASPECTOS HISTÓRICO-CULTURAL DA APRENDIZAGEM DOS DEFICIENTES}

Ao referir o entendimento qualitativo a respeito do desenvolvimento e da aprendizagem de crianças surdas-mudas, cegas e deficientes intelectuais, os escritos defectológicos ${ }^{3}$ de Vygotsky registrados no começo do século $X X$ concentraram-se na importância da educação social e no potencial das crianças deficientes em se desenvolverem normalmente (VAN DER VEER; VALSINER, 1996; SILVA et al., 2013).

Segundo Vygotsky, a educação social promove no educando deficiente um processo de compensação social através da apropriação cultural, quando realizada de modo planejado e objetivo (NUERNBERG, 2008). Essa concepção aposta que a inteligência não é estática, mas sim dinâmica, podendo evoluir a partir das trocas constantes com o ambiente. Assim, a educação escolar se insere neste contexto como chave principal para a determinação da Zona de Desenvolvimento Proximal ${ }^{4}$ das crianças deficientes (COSTA, 2006).

Segundo Vygotsky (1997):

\footnotetext{
${ }^{3}$ Defectologia - termo utilizado para a ciência que estudava crianças com vários tipos de problemas ("defeitos") mentais e físicos (Van Der Veer e Valsiner, 1996).

${ }^{4}$ Zona de Desenvolvimento Proximal - Segundo Vygostky (1989), é "a distância entre o nível de desenvolvimento real, que se costuma determinar através da solução independente de problemas e o nível de desenvolvimento potencial, determinado através da solução de problemas sob orientação de um adulto ou em colaboração com companheiros mais capazes".
} 


\begin{abstract}
A educação de crianças com diferentes deficiências deve basear-se em que, simultaneamente com a deficiência também estão dadas as tendências psicológicas de orientação oposta, estão dadas as potencialidades compensatórias para superar a deficiência e que precisamente são estas as que saem em primeiro plano no desenvolvimento da criança e devem ser incluídas no processo educativo como sua força motriz.
\end{abstract}

Esse processo educativo compreende: os processos de interações que ocorrem entre alunos e alunos, alunos e professor e entre os alunos e matérias, equipamentos, recursos pedagógicos e com o próprio sujeito através de suas aprendizagens anteriores (TOLEDO; MARTINS, 2009).

Conforme Padilha (2004):

[...] a transformação de um processo dá se de um funcionamento interpessoal (social) para o intrapessoal, isto é, de que as ações do sujeito são sempre mediadas pelo outro e passam ao plano intrapessoal pelo processo de internalização.

Deste modo, as relações sociais tornam-se funções psicológicas por meio de processos de internalizações que ocorrem com a assimilação e a reelaboração da linguagem que vai se constituindo através das significações do mundo simbólico/linguístico de forma que haja a constituição/organização do pensamento (KASSAR, 2000).

\title{
PROCESSO DE ESCOLARIZAÇÃO DOS DEFICIENTES VISUAIS
}

A educação de deficientes visuais originou-se na França durante o século XVII, com a escola Instituto Real dos Jovens Cegos de Paris fundado por Valentin Haüy. Em consonância, no Brasil o atendimento aconteceu com a criação do Instituto Benjamin Constant (Instituto dos Meninos Cegos) e do Instituto Nacional de Surdos e Mudos, situados no Rio de Janeiro e estabelecidos pelo Decreto Imperial $\mathrm{n}^{\circ} 1.428$ do Imperador Dom Pedro II (MIRANDA, 2004; NUNES; LOMÔNACO, 2010).

O processo de escolarização e desenvolvimento social, bem como a escrita e a leitura para os cegos, só foi permitido a partir do Sistema Braile criado em 1829 na França por Luis Braille (ORRICO et al., 2009). Esse sistema de escrita e leitura para cegos no Brasil começou com a Fundação do Livro do Cego no Brasil em 1946, atualmente conhecida como Fundação Dorina Nowill (YONASHIRO, 2017).

Além disso, a Declaração de Salamanca trouxe propostas de práticas, políticas e princípios direcionados a Educação para todos garantida na Conferência Mundial em Educação Especial em cooperação com a UNESCO, realizada pelo governo da Espanha em Salamanca no ano de 1994 (MACHADO et al., 2005).

Mais tarde, a Lei de Diretrizes e Bases da Educação Nacional (LDBEN nº 9.394) foi promulgada, em 1996, no Brasil. Essa lei assegura a matrícula preferencialmente no sistema regular de ensino e os apoios especializados necessários sobre responsabilidade do poder público para as pessoas com deficiência e os grupos minoritários em geral (FERREIRA, 2000). 
Diante disso, novas adaptações no processo de escolarização e educação dos deficientes visuais foram oferecidas de forma autêntica para o desenvolvimento da autonomia e independência do sujeito, proporcionando a "superação dos impactos e dos prejuízos decorrentes da limitação visual, seja perda total ou perda parcial da visão, bem como, dos estigmas socialmente concebidos à deficiência visual" (ACIEM ; MAZZOTTA, 2013).

Uma vez que a concepção de uma pessoa que nunca enxergou diferencia das experiências perceptivas daquela que perdeu a visão ao longo da vida (MASINI, 2003), o educador necessita, então, compreender o relacionar dos alunos deficientes visuais com o mundo que os cerca, para, então, mediar o processo de aprendizagem destes educandos (JUNIOR; HERNANDES, 2011).

Para isso, a aprendizagem deve ser adequada a cada especificidade do aluno de forma que responda a atribuição de significações e da construção do novo conhecimento. Neste caso,

O deficiente visual tem uma dialética diferente, devido o conteúdo - que não é visual, e a sua organização cuja especificidade é a de referir-se ao tátil, auditivo, olfativo, cinestésico. É a dialética entre o especifico e o geral que se define a estrutura psíquica, integrada ou não (MANTOAN, 1997).

Como a visão tem ação integradora na construção e formação dos conceitos e linguagem, Cunha e Enumo (2003) relatam que:

O processo de desenvolvimento da criança deficiente visual, a restrição de habilidade de exploração, assim como as influencias psicológicas da própria criança e do ambiente começam desde o nascimento a moldar o seu desenvolvimento.

Assim sendo, o impacto das alterações visuais acarreta atrasos no desenvolvimento neuropsicomotor dos indivíduos por falta da integração das atividades motoras, perceptivas e mentais (SOUZA et al., 2010).

Já que uma parcela dos alunos que compõem a educação básica é deficiente visual e essa representação no Brasil equivale mais de 6,5 milhões de pessoas, sendo 582 mil cegos e seis milhões com baixa visão, segundo os dados da Fundação Dorina Noeill com base no Censo 2010, feito pelo Instituto Brasileiro de Geografia e Estatística (IBGE) (BRASIL, 2015), esse estudo teve como objetivo analisar como o conteúdo de Embriologia Humana tem sido trabalhado com alunos deficientes visuais matriculados em salas de ensino regular nas escolas estaduais do município de São Mateus-ES. Foram analisados: (1) o aprendizado dos alunos deficientes visuais (cegueira e baixa visão) quanto ao conteúdo de Embriologia Humana de forma qualitativa; (2) os métodos/recurso didáticos utilizados pelos professores para trabalhar o conteúdo de Embriologia Humana com alunos esses alunos; (3) quais recursos didáticos estão disponíveis nas escolas para atendimento 
dos alunos deficientes visuais e (4) as dificuldades encontradas pelos professores em ensinar embriologia para os alunos deficientes visuais.

\section{MATERIAL E MÉTODOS}

O presente estudo tratou-se de uma pesquisa qualitativa e foi desenvolvida em três escolas estaduais da rede pública do município de São Mateus-ES. Foram escolhidas as escolas onde havia alunos deficientes visuais matriculados, após levantamento realizado na Superintendência Regional de Educação de São MateusES.

Por ser um estudo de caráter investigativo o Comitê de Ética em Pesquisa do Centro Universitário Norte do Espírito Santo (CEP/UFES) apreciou e aprovou o presente estudo (CEP/UFES: 72259917.0.0000.5063). Os participantes, professores do ensino de Ciências e Biologia e os alunos deficientes visuais matriculados na rede regular de ensino foram informados sobre os objetivos e as etapas do estudo e autorizaram a divulgação dos dados através do Termo de Consentimento Livre e Esclarecidos.

A coleta de dados foi realizada através de entrevistas orientadas gravadas em áudio com três professores da área de Ciências e Biologia, um professor especializado em Atendimento Educacional Especializado (AEE) e quatro alunos portadores da deficiência visual (cegueira e baixa visão) para conhecer e compreender o grau de entendimento do conteúdo de Embriologia Humana pelos alunos deficientes visuais e a forma como é ensinado pelos professores na educação básica. Os participantes foram identificados com um código para manter o sigilo da identidade, sendo " $P$ " referente aos professores e " $A$ " os alunos.

Os dados obtidos durantes as gravações foram submetidos à análise de conteúdo, conforme a proposta de Bardin (1977) e análise de discurso segundo Amaral (2007).

\section{CONTEXTO DO ALUNO}

\section{RESULTADOS E DISCUSSÃO}

No que refere as análises de aprendizagem dos alunos em relação ao conteúdo de embriologia, notou-se uma aprendizagem bem superficial do conteúdo. O aluno A1 relatou que: "Foi ensinado bem básico, só a parte de espermatogênese, fecundação e evolução do bebê". Esses dados reforçam a existência de dificuldades no ensino de embriologia tanto por parte dos professores em ensinar o conteúdo quanto dos alunos no processo de compreensão do mesmo, necessitando de desenvolvimento de novas metodologias que contribuam com a qualidade das aulas e, consequentemente, o aprendizado.

Outro fator relatado pelos estudantes entrevistados está na dificuldade de não enxergarem bem, o que atrapalha o processo de ensino e aprendizagem do conteúdo, também observado por outros autores (CARVALHO et al., 1998) e marcado pelo estudante A2 ao queixar-se do tamanho da fonte " [...] não consigo ler, mesmo com os óculos". Assim, torna-se necessário o uso de modelos didáticos ou 
materiais adaptados como forma heterogênea de aproximação da dissertação oral do discente (FREITAS et al., 2008).

Os recursos empregados pelos professores em sala para ensinar o conteúdo de embriologia conforme os relatos dos estudantes A1, A2 e A4 concentram-se no uso de vídeos, slides, biblioteca, laboratório, maquete e modelos didáticos. No entanto, o uso frequente do livro didático e do quadro branco, de acordo com a abordagem dos estudantes A2, A3 e A4, contextualiza um cenário exclusivo por não atender a demanda dos deficientes visuais, seja de baixa visão ou cegueira.

Assim, observa-se carência de metodologias alternativas inseridas em sala para atender os alunos e sustenta o discurso do aluno A3 ao dizer que o conteúdo é acompanhado pelo livro didático. Os alunos A1, A2 e A3 afirmaram que ocorre a ampliação de fonte somente no momento da prova. Já o aluno A1 relatou que "uma vez fiz prova oral". Esses dados confirmam a necessidade do uso de metodologias diferenciadas para a formação conceitual do objeto que está, na maioria das vezes, destacado somente em recurso verbal que sobrepõe a experiência do deficiente visual (MORAES, 2009).

Por outro lado, os recursos pedagógicos oferecidos pelas escolas como suporte para o desenvolvimento da aprendizagem e ensino das disciplinas concentram-se na sala de recurso com um profissional especializado e como apoio, conforme relato dos alunos A1, A2 e A4. Contudo, as atividades realizadas são de caráter extracurricular $\mathrm{e}$, na maioria das vezes, não conecta com o conteúdo visto em sala. Assim, constatou-se que as escolas ainda carecem de muitas mudanças que devem ser incorporadas na política coletiva da instituição, de modo específico no Projeto Político Pedagógico, para que haja a concretização de uma gestão escolar democrática com serviços e propostas educativas abertas e flexíveis que atenda as necessidades de mudanças da escola referente aos recursos pedagógicos (MACIEL, 2000; ROPOLI et al., 2017). Essa abordagem estende-se para as observações realizadas pelos alunos quanto à interação social com a classe escolar (Quadro 1).

QUADRO 1: Interação dos alunos deficientes visuais com os demais alunos da classe.

\begin{tabular}{|c|l|}
\hline CATEGORIA & \multicolumn{1}{|c|}{ CONTEÚDO } \\
\hline Bom & $\begin{array}{l}\text { A1: "Sempre foi normal. Quando eu tinha dificuldades eles me ajudavam, } \\
\text { quando era para copiar alguma atividade que eu tinha dificuldade eles me } \\
\text { ajudavam". } \\
\text { A4: "Eu gosto". }\end{array}$ \\
\hline Regular & A2: “Assim, às vezes tem uns problemas né. As vezes um vai e faz piadinha”. \\
\hline Ruim & $\begin{array}{l}\text { A3: "Não dou bem com a minha turma, mas não é pelo fato da minha } \\
\text { deficiência”. }\end{array}$ \\
\hline
\end{tabular}

\section{CONTEXTO DO PROFESSOR}

As principais dificuldades dos professores ao ensinar embriologia para os alunos deficientes visuais encontram-se no momento de demonstrar o conteúdo de 
modo que o aluno consiga assimilar, associar e criar representações sobre o que está sendo exposto, por ser microscópico, já que não pode ser visto pelos alunos deficientes visuais (Quadro 02). Com isso, reforça-se a necessidade de recursos didáticos auxiliares no processo de ensino e aprendizagem, como descrito por Masini (1992).

QUADRO 2: Dificuldades dos professores da educação básica em ensinar embriologia para deficientes visuais.

\begin{tabular}{|c|l|}
\hline $\begin{array}{c}\text { CATEGORI } \\
\text { A }\end{array}$ & \multicolumn{1}{c|}{ CONTEÚDo } \\
\hline Difícil & $\begin{array}{l}\text { P2: "A mesma coisa da citologia é difícil. [...] não temos material 3D, alto-relevo, } \\
\text { nada pra isso". }\end{array}$ \\
\hline & $\begin{array}{l}\text { P1: "Pior. [...] você falar de um embrião, de um folheto embrionário, algo que você } \\
\text { não consegue ver, tatear, tocar. A questão do visualizar, da construção da imagem } \\
\text { é muito complicada". } \\
\text { Puito difícil "Todas. [...] nem para o que esta enxergando o esquema ou imagem não é } \\
\text { garantia de que ele vá aprender o conteúdo. Então para o que não consegue } \\
\text { enxergar é complicado, acho que é essa a maior dificuldade". }\end{array}$ \\
\hline
\end{tabular}

Os métodos/recursos utilizados pelos professores tanto para o processo de ensino e aprendizagem quanto para a avaliação são os mesmos usados para os alunos normovisuais (Quadro 03). O professor P3 relatou que já trabalhou com um aluno que não conseguia acompanhar o livro didático e nem fazer as atividades, e afirmou que não usou de metodologias alternativas e que "a única diferença que tinha era na impressão e na escrita de alguma coisa”. Já o professor P1 teve uma experiência com um aluno cego e a assistência foi muito boa. Em seu discurso esse professor relatou que: "Ele tinha a máquina de Braile e durante as minhas aulas ele anotava tudo o que falava".

Assim, confirmam-se as dificuldades por parte dos docentes em suas práticas pedagógicas, que advêm de uma série de lamentações, entre estas a falta de capacitação e despreparo, por não terem recebido tal formação em seus cursos de graduação, além da carência de recursos disponibilizados pela escola que atenda às distintas formas de aprendizagem do alunado (GLAT; NOGUEIRA, 2003). 
QUADRO 3: Métodos/recursos utilizados em sala para ensinar os alunos.

\begin{tabular}{|c|c|}
\hline CATEGORIA & CONTEÚDO \\
\hline Método & $\begin{array}{l}\text { P1: "é o livro didático que eles têm acesso e eu busco na internet slides, vídeos, } \\
\text { alguma coisa para despertar o interesse maior, basicamente é isso". } \\
\text { P2: "O aluno de baixa visão eu aumento fonte, sento ao lado, faço prova } \\
\text { diferenciada. Agora o que não tem visão a gente faz uma avaliação oral para } \\
\text { adquirir alguma informação do que foi aprendido e da uma nota". } \\
\text { P3: "procuro fazer uma aula prática, uma dinâmica". }\end{array}$ \\
\hline Recursos & $\begin{array}{l}\text { P1: "Eu utilizo o áudio visual, o data show, slides, vídeo-aulas, vídeo e o quadro } \\
\text { para escrever". } \\
\text { P3: "Slide, livro, filme”. }\end{array}$ \\
\hline
\end{tabular}

Os recursos/suportes disponibilizados pelas escolas da rede estadual para trabalhar com deficientes visuais são considerados limitados e direcionados somente à sala de recursos, com um profissional apto para atender as especificidades dos alunos (Quadro 04).

QUADRO 4: Recursos/suportes disponibilizados pelas escolas da rede estadual para os deficientes visuais

\begin{tabular}{|c|l|}
\hline CATEGORIA & \multicolumn{1}{|c|}{ CONTEÚDO } \\
\hline Pouco & P1: "Tem uma sala de recursos". \\
\hline Muito pouco & $\begin{array}{l}\text { P2: "A gente acaba aumentando o tamanho de fonte, de letra para que } \\
\text { consiga ver também. Agora o que é totalmente cego. Só o que a escola } \\
\text { oferece, o estado tem um kit para deficientes visuais. Esse kit é um geral, não } \\
\text { sendo específico para a biologia”. }\end{array}$ \\
\hline
\end{tabular}

Essa oferta dos serviços e atendimentos garantidos pelo Centro de Apoio Pedagógico às Pessoas com Deficiência Visual assegura as "escolas e aos estudantes com deficiência visual e surdocegueira o atendimento educacional em tempo hábil, com produção e distribuição de livros didáticos, paradidáticos e literários em Braille, tipo ampliado, áudio e Mecdaisy, kit cegueira e baixa visão, de forma a apoiar o processo ensino-aprendizagem, além de oferecer condições adequadas para o pleno desenvolvimento de suas potencialidades, levando-os à autonomia, independência e inclusão social" (BRASIL, 2016).

O mesmo professor especializado em AEE (P4) atendia três dos quatros alunos participantes da pesquisa em suas diferentes escolas e relatou que como método: "Tem uns programas em áudio, mas o que eu somente uso aqui na sala de recursos é o Dosvox e o Mcdaisy. Mas na sala regular é mais ampliação de texto, de provas, do que é necessário". Além disso, P4 deixou claro que: "Na baixa visão cada aluno é tratado de uma forma. Cada patologia tem suas especificidades, mesmo com a mesma patologia. É feito um plano individual pra cada um".

Carvalho et al. (2002) asseguram que o professor especializado da sala de recursos tem papel essencial no auxilio das atividades escolares e na inclusão efetiva dos alunos deficientes visuais pelo fato dos professores do ensino regular e as escolas não terem informação adequada sobre o aluno com deficiência.

Mansini (1993) aponta a necessidade do professor da sala de recursos em acompanhar e assessorar o professor da classe comum, para que haja uma ENCICLOPÉDIA BIOSFERA, Centro Científico Conhecer - Goiânia, v.15 n.27; p. 2018204 
adaptação do método aplicado na turma regular para os alunos deficientes visuais. Esta adaptação seria por meio da utilização de recursos e materiais específicos que atendam aos mesmos conteúdos abordados na classe comum com os outros alunos. Porém, segundo os relatos dos professores, não é comum esta interação nas escolas de São Mateus/ES.

Por fim, os professores relataram que o processo de inclusão dos deficientes visuais na rede regular de ensino resume-se na falta de preparo do docente, disponibilidade de recursos didáticos, falta de estrutura física e suporte/condição de trabalho (Quadro 05). Além disso, os discursos apontaram que a escola não está preparada para incluir, embora, a interação social dos alunos deficientes visuais com os demais alunos e com todo corpo escolar tenha sido classificada como satisfatória.

QUADRO 5: O olhar do professor sobre o processo de inclusão dos deficientes visuais no ensino básico.

\begin{tabular}{|c|c|}
\hline CATEGORIA & CONTEÚDO \\
\hline Escolar & $\begin{array}{l}\text { P1: “(...) inclusão no ponto de vista do processo de ensino e aprendizagem, não. } \\
\text { Não existe estrutura, não existe suporte, não existe interesse do governo em } \\
\text { resolver o problema". } \\
\text { P2: "Não. Eu falo que é uma inclusão de mentira, pois incluir o aluno e não dar } \\
\text { condição de trabalhar". } \\
\text { P3: "A escola não esta pronta em nenhum sentido, não tem estrutura física, não tem } \\
\text { preparo de docente. A escola não esta preparada para incluir". }\end{array}$ \\
\hline Social & $\begin{array}{l}\text { P1: "Inclusão do ponto de vista da interação social, sim". } \\
\text { P2: “(...) participam junto com colegas, perguntam". } \\
\text { P3: "Vou te falar que os meninos aceitam muito bem. Os meninos ajudavam, } \\
\text { mesmo que não precisa, porque é o ambiente comum deles". }\end{array}$ \\
\hline
\end{tabular}

\section{CONCLUSÃO}

Neste estudo, observou-se a necessidade de incorporar novos recursos pedagógicos no processo de ensino e aprendizagem do conteúdo de embriologia, já que é considerado de grande dificuldade de ser ensinado por parte dos professores e de aprendizado para os alunos.

Assim, a escola precisa estruturar o espaço físico, político, pedagógico e curricular na tentativa de amenizar o número de evasão dos alunos deficientes visuais e as dificuldades encontradas no exercício da docência banalizada em condições impróprias de trabalho, com cargas horárias excessivas, tempo de planejamento mínimo e salas superlotadas. Além disso, sugere-se capacitação/formação continuada de professores e gestores, disponibilidade de instrumentos/ferramentas pedagógicas a todos os educandos, além da construção de um planejamento educacional coletivo com a família, sociedade e escola.

\section{REFERÊNCIAS}

ABENHAIM, F. Os caminhos da inclusão: breve histórico. In: Psicologia e direitos humanos: educação inclusiva, direitos humanos na escola. 2 ed. São Paulo: Casa do Psicólogo, p. 39-54, 2005.

ACIEM, T. M.; MAZZOTTA, M. J. S. Autonomia pessoal e social com deficiência visual após reabilitação. Revista Brasileira de Oftalmologia, v.72, n.4, p.7-261, 2013. Disponível em: < http://dx.doi.org/10.1590/S0034-72802013000400011>. doi:10.1590/S0034-7280201300040001. 
AMARAL. M. V. B. O avesso do discurso: análise de práticas discursivas no campo do trabalho. Maceió: EDUFAL, p. 1-97, 2007

BARDIN, L. Análise de Conteúdo. ed.70. 1977.

BRASIL. Diretrizes nacionais para a educação especial na educação básica. Secretaria de Educação Especial. Brasília (DF), MEC, SEESP, 2001. Disponível em: < http://portal.mec.gov.br/seesp/arquivos/pdf/diretrizes.pdf>.

BRASIL. Formação Continuada a Distância de Professores para o Atendimento Educacional Especializado: Deficiência visual. Brasília (DF), MEC, SEED, SEEP, 2007. Disponível em: < http://portal.mec.gov.br/seesp/arquivos/pdf/aee_dv.pdf >.

BRASIL. Alunos cegos e com baixa visão: Orientações curriculares. Direção Geral e de Desenvolvimento Curricular: Direção de Serviços da Educação Especial e do Apoio Sócio-Educativo. Brasil (DF), MEC, DGIDC, 2008. Disponível em: <http://www.deficienciavisual.pt/x-txt-aba-OrientacoesCurricularesCegosBxV.pdf>.

BRASIL. Braile aumenta inclusão de cegos na sociedade. Texto disponibilizado em 5 jan 2015. Disponível em: < http://www.brasil.gov.br/cidadania-ejustica/2015/01/braile-aumenta-inclusao-de-cegos-na-sociedade>. Acesso em 23 abr. 2017.

BRASIL. Centro de Apoio Pedagógico às Pessoas com Deficiência Visual: Histórico e Diretrizes de Funcionamento. Texto disponibilizado em 19 out 2016. Disponível em: $<$ http://seeensinoespecial.educacao.mg.gov.br/images/stories/easygallery/capcentro-de-apoio-pedagogico-as-pessoas-com-deficiencia-visual.pdf> Acesso em: 27 jan. 2017.

BATISTETIL, C. B.; CAMARGO, E. P.; ARAUJO, E. S. N. N.; CALUZI, J. J. Uma discussão sobre a utilização da história da ciência no ensino de célula para alunos com deficiência visual. In: VII Encontro Nacional de Pesquisa em Educação e Ciências. $\quad 2009 . \quad$ Dlorianópolis. <http://posgrad.fae.ufmg.br/posgrad/viienpec/pdfs/302.pdf>.

CARVALHO, K. M. M.; FREITAS, C. C.; KIMOLTO, E. C.; GASPARETTO, M. E. R. F. Avaliação e conduta em escolares portadores de visão subnormal atendidos em sala de recursos. Revista Brasileira de Oftalmologia, v.65, n.4, p. 445-449, 2002. Disponível em: < http://dx.doi.org/10.1590/S0004-27492002000400010>. doi: 10.1590/S0004-27492002000400010.

CARVALHO, K. M. M.; MINGUINI, N.; MOREIRA FILHO, D. C.; KARA-JOSÉ, N. Characteristics of a pediatric low-vision population. Jornal Pediatric Ophthalmology and Strabismus, v.35, p. 162-165, 1998. Disponível em: https://doi.org/10.3928/0191-3913-19980501-09>. doi:10.3928/0191-3913-1998050109. 
CUNHA, A. C. B.; ENUMO, S. R. F. Desenvolvimento da criança com deficiência visual (DV) e interacção mãe-criança: algumas considerações. Psicologia, Saúde e Doença, v.4, n.1, p.33-46, 2003. Disponível em: $<$ http://webcache.googleusercontent.com/search?q=cache:MoG02KJ1--kJ:spps.pt/uploads/jornal/45.pdf+\&cd=1\&hl=pt-BR\&ct=clnk\&gl=br> .

COSTA, D. A. F. Superando Limites: A Contribuição de Vygotsky para a Educação Especial. Revista Psicopedagogia. v.23, n.72, p.232-240, 2006. Disponível em: $<$ http://pepsic.bvsalud.org/scielo.php?script=sci_arttext\&pid=S0103$84862006000300007>$.

FERNANDES, E. M.; ORRICO, H. F. Acessibilidade e Inclusão Social. Rio de Janeiro: Descubra, 2008.

FERREIRA, J. R. Políticas Educacionais e Educação Especial. São Paulo. Reunião Anual de ANPED, p. 1-13, 2000. Disponível em: <http://23reuniao.anped.org.br/textos/te15.PDF>.

FREITAS, L. A. M.; BARROSO, H. F. D.; RODRIGUES, H. G.; AVERSI-FERREIRA, T. A. Construção de modelos embriológicos com material reciclável para uso didático. Bioscience Journal, v. 24, n. 1, p. 91-97, 2008. Disponível em: <http://www.seer.ufu.br/index.php/biosciencejournal/article/view/6732/4443>.

GLAT, R.; NOGUEIRA, M. L. L. Políticas Educacionais e a Formação de Professores para a Educação Inclusiva no Brasil. Comunicações: Programa da Pós Graduação em Educação, v. 10, n.1, 2003. Disponível em: <http://dx.doi.org/10.15600/2238121X/comunicacoes.v10n1p134-142>. doi: 10.15600/2238-121X.

GLAT, R.; FERNANDES, E. M. Da Educação Segregada à Educação Inclusiva: uma Breve Reflexão sobre os Paradigmas Educacionais no Contexto da Educação Especial Brasileira. Inclusão, Revista da Educação Especial, Brasília, n.1, p. 35-39, $2005 . \quad$ Disponível em: <https://pt-static.zdn.net/files/df5/ac5f60b62303b5061bfba7c01690e129.pdf>.

GLAT, R.; BLANCO L. M. V. Educação Inclusiva: Cultura e Cotidiano Escolar. In: Educação Especial no contexto de uma Educação Inclusiva. 2 ed. Rio de Janeiro: 7Letras, p. 15-35, 2009.

JUNIOR, K. S.; HERNANDES, R. B. As dimensões do não ver: Formação continuada de educadores e a profissionalização das pessoas com deficiência visual. São Paulo: Editora Unesp, 2011.

KASSAR, M. C. M. Marcas da historia social no discurso de um sujeito: Uma contribuição para a discussão a respeito da constituição social da pessoa com deficiência. Cadernos Cedes, vol. 20, n. 50, p.41-54, 2000. Disponível em: <http://dx.doi.org/10.1590/S0101-32622000000100004>. doi:10.1590/S010132622000000100004. 
MACHADO, A. M.; NETO, A. J. V.; NEVES, M. M. B. J.; SILVA, M. V. O.; PRIETO, R. G.; RANÑA, W.; ABENHAIM, E. Psicologia e direitos humanos: educação inclusiva, direitos humanos na escola. 2 ed. São Paulo: Casa do Psicólogo, p. 125158, 2005.

MACIEL, M. R. C. Portadores de deficiência a questão da inclusão. São Paulo em Perspectiva, v.14, n.2, p. 51-56, 2000. Disponível em: < http://dx.doi.org/10.1590/S0102-88392000000200008>. doi:10.1590/S010288392000000200008.

MAIA, T. A. C.; DIAS, N. R. M., LIMA, M. V. F.; FREIRES, J. G. J.; SANTOS, L. S.; GIRAO, V. C. C. Análise do processo de ensino-aprendizagem de embriologia a partir de recursos de desenho. Revista Encontros Universitários da UFC, v. 2, n. 1, 2017. Disponível em: < http://www.periodicos.ufc.br/eu/issue/view/587/showToc>.

MANTOAN, M. T. E. Ensinando a turma toda as diferenças na escola. Pátio- revista pedagógica, v. $\mathrm{V}, \quad \mathrm{n} .20$, p. 18-23, 2002. Disponível em: < http://www.lite.fe.unicamp.br/papet/2003/ep403/ensinando_a_turma_toda.htm>.

MANTOAN, M. T. E. A integração de pessoas com deficiência: contribuições para uma reflexão sobre o tema. São Paulo: Memnon. Editora SENAC. SP, 1997.

MANSINI, E. F. S. A educação do portador de deficiência visual: as perspectivas do vidente e do não vidente. Em aberto. Brasília, v.13, n. 60, p.61-76, 1993. Disponível em: < http://emaberto.inep.gov.br/index.php/emaberto/article/viewFile/1917/1888>.

MASINI, E. F. S. A experiência perceptiva é o solo do conhecimento de pessoas com e sem deficiências sensoriais. Psicologia em Estudo. Maringá. v.8, n.1, p.3943, 2003. Disponível em: <http://dx.doi.org/10.1590/S1413-73722003000100006>. doi:10.1590/S1413-73722003000100006.

MASINI, E. F. S. O perceber e o relacionar-se do deficiente visual: orientando professores especializados. Revista Brasileira de Educação Especial, v. 1, 1992. Disponível em:

http://www.abpee.net/homepageabpee04_06/artigos_em_pdf/revista1 numero1pdf/r1 _art03.pdf>.

MATOS, S. A.; COUTINHO, F. A.; CHAVES, A. C. L.; COSTAS, F. J.; AMARAL, F. C. Referencias teórico-metodológicos para a análise de relação texto-imagem do livro didático de Biologia: Um estudo sobre o tema de embriologia. Revista Brasileira de Ensino de Ciências e Tecnologia, v.3, n.1, p. 92-114, 2010. Disponível em: <https://periodicos.utfpr.edu.br/rbect/article/view/574>. doi:10.3895/S1982-873X2010000100006.

MENDES, E. G.; GRAVENA, A. C.; CORSI, G.; SERRA, M. N. A percepção do processo de escolarização de alunos com necessidades educativas especiais 
inseridas no ensino regular. Revista Inclusão, n.1, 2005. Disponível em: <http://23reuniao.anped.org.br/textos/1502t.PDF>.

MENDES, E. G. A radicalização do debate sobre inclusão escolar no Brasil. Revista Brasileira de Educação, v.11, n.33, p. 387-405, 2006. Disponível em: <http://dx.doi.org/10.1590/S1413-24782006000300002>. doi:10.1590/S141324782006000300002.

MIRANDA, A. A. B. História, deficiência e educação especial. Revista HISTEDBR On-line, Campinas, n.15, p.1-7, 2004. Disponível em: $<$ http://atividadeparaeducacaoespecial.com/wp-content/uploads/2014/09/INCLUS \%C3\%83O-DEFICENCIA-E-EDUCA\%C3\%87\%C3\%83O-ESPECIAL.pdf>.

MORAES, D. F. P. Artes visuais para deficientes visuais: o papel do professor no ensino de desenho para cegos. In: V Encontro do Grupo de Pesquisa Educação, Arte e Inclusão, Tecnologias e Materiais Educativos no Contexto Inclusivo (pp. 27-38). Santa Catarina: Florianópolis. 2009. Disponível em: $<$ https://virtual.udesc.br/eventos/vencontro/03_artes_visuais.pdf>.

NUERNBERG, A. H. Contribuições de Vigotski para a Educação de pessoas com Deficiência Visual. Psicologia em Estudo. Maringá, v.13, n.2, p.307-316, 2008. Disponível em: <http://dx.doi.org/10.1590/S1413-73722008000200013>. doi:10.1590/S1413-73722008000200013.

NUNES, S.; LOMÔNACO, J. F. B. O aluno cego: preconceitos e potencialidades. Revista Semestral da Associação de Psicologia Escolar e Educacional. São Paulo. v.14, n.1, p.55-64, 2010. Disponível em: <http://www.scielo.br/pdf/pee/v14n1/v14n1a06>.

OLIVEIRA, A. A. Construção de modelos didáticos para o ensino do desenvolvimento embrionário humano. Arquivo do Mudi, v.19, n.1,p-1-10, 2015. Disponível em: < http://dx.doi.org/10.4025/arqmudi.v19i1.28172>. doi: 10.4025

ORRICO, H.; CANEJO, E. FOGLI,B. Educação Inclusiva: Cultura e Cotidiano Escolar. In: Uma reflexão sobre o cotidiano escolar de alunos com deficiência visual em classes regulares. 2 ed. Rio de Janeiro: 7Letras, p. 116-136, 2009.

PACHECO, J.; EGGERTSDÓTTIR, R.; MARINÓSSON, L. G. Caminhos para a inclusão: um guia para o aprimoramento da equipe escolar. Porto Alegre: Artmed, 2007.

PADILHA, A. M. L. Possibilidades de história ao contrário, ou, como desencaminhar o aluna da classe especial. 3 ed. São Paulo: Plexus Editora, 2004.

RODRIGUES, A. L. M.; FIEDLER, P. T.; SANTOS, S. H. P. D.; PEROTTA, B.;HIROSE, T. E.; OLIVEIRA, S. A. D.; SATO, M. H.; ÁVILA, H. S.; MORAES, T. C. D.; FERREIRA, F. D. F. I. Embriologia prática: uma lição diferente. Arquivo do Apadec, Maringá, v. 8, supl. 2, p. 11, 2004. 
ROPOLI, E. A.; MANTOAN, M. T. E.; SANTOS, M. T. C. T.; MACHADO, R. A educação especial na perspectiva da inclusão social e escola comum inclusiva. Disponível em: <https://xa.yimg.com/kq/groups/20937900/648381784/name/AEE_A+Escola+Comu m+na+Perspectiva+Inclusiva.pdf>. Acesso em: 30 nov. 2017.

SÁNCHEZ, P. A. A educação inclusiva: um meio de construir escolas para todos no século XXI. Inclusão - Revista da Educação Especial, 2005. Disponível em:< http://portal.mec.gov.br/seesp/arquivos/pdf/revistainclusao1.pdf>. Acesso em: 06 nov. 2017.

SILVA, M. A. J.; TRAZZI, P. S. S.; SANTOS, J. A. A construção de modelos no ensino de Biologia: uma experiência na formação inicial de professores. In: $\mathbf{X}$ Encontro Nacional de Pesquisa em Educação em Ciências (pp. 1-8). São Paulo. 2015. Disponível em: <http://www.abrapecnet.org.br/enpec/xenpec/anais2015/resumos/R1069-1.PDF>.

SILVA, F. G.; MENEZES, H. C. S.; OLIVEIRA, D. A. Um estudo sobre a defectologia na perspectiva Vigotskiana: A aprendizagem do deficiente intelectual em reflexão. In:

II Seminário Internacional de Representações Sociais, IV Seminário Internacional sobre Profissionalização, (pp. 20217-20229). Curitiba: PUCPR. 2013. Disponível em: < http://educere.bruc.com.br/ANAIS2013/pdf/9698_6556.pdf>.

SOUZA, P. F.; FARIA, J. C. N. M. A construção e avaliação de modelos didáticos para o ensino de ciências morfológicas: Uma proposta inclusiva e interativa. Enciclopédia Biosfera: Centro Científico Conhecer. Goiânia. v.7, n.13. p.15501562, 2011. Disponível em: < http://www.conhecer.org.br/enciclop/2011b/human.htm>.

SOUZA, T. A.; SOUZA, V. E.; LOPES, M. C. B.; KITADAI, S. P. S. Descrição do desenvolvimento neuropsicomotor e visual de crianças com deficiência visual. Arquivo Brasileiro de Oftalmologia, v. 73, n.6, p. 526-530, 2010. Disponível em: <http://dx.doi.org/10.1590/S0004-27492010000600012>. doi:10.1590/S000427492010000600012.

SOUZA, A. D.; BOSCA, C. A.; HUGO, C. N. As Relações entre deficiência visual congênita, conduta do espectro do autismo e estilo materno de Integração. Revista de Estudos de Psicologia, v. 22, n. 4, p. 355-364, 2005. Disponível em: <http://dx.doi.org/10.1590/S0103-166X2005000400003>. doi:10.1590/S0103166X2005000400003.

TOLEDO, E. H.; MARTINS, J. B. A atuação do professor diante do processo de inclusão e as contribuições de Vygotsky. In: IX Congresso Nacional de Educação, III Encontro Sul Brasileiro de Psicopedagogia, (pp. 4126- 4138). Curitiba: PUCPR. $2009 . \quad$ Disponível em: <http://educere.bruc.com.br/arquivo/pdf2009/3298_1675.pdf>. 
VAN DER VEER, R.; VALSINER, J. Vygotsky: uma síntese. São Paulo: Loyola, 1996.

VYGOTSKI, L. S. Obras Escogidas. V - Fundamentos de defectologia. Tradução Júlio Guillermo. Blank. Madrid: Visor, 1997.

VYGOTSKY, L. S. Fundamentos de defectologia. Havana: Editorial Pueblo y Educación, 1989.

YONASHIRO, M. Fundação Dorina Nowill para cegos. 2017. Disponível em: $<$ https://www.fundacaodorina.org.br/blog/71-anos-de-historias/>. Acesso em: 27 nov. 2017. 